\title{
O Ter e o Ser: Representações Sociais da Adolescência entre Adolescentes de Inserção Urbana e Rural
}

\author{
Priscilla de Oliveira Martins \\ Zeidi Araújo Trindade \\ Universidade Federal do Espírito Santo \\ Ângela Maria de Oliveira Almeida
}

Universidade de Brasilia

\begin{abstract}
Resumo
Fundamentando-se na Teoria das Representações Sociais este trabalho analisa como adolescentes de diferentes inserções sociai representam a adolescência e dão sentido ao período em que vivem. Participaram desse estudo 360 adolescentes entre as idades de 14 e 23 anos: 180 (90 do sexo feminino e 90 do sexo masculino) residentes em região urbana, estudantes de escola particular, localizada em bairro considerado de classe média alta e alta, e 180 (90 do sexo feminino e 90 do sexo masculino) residentes em uma regĩo burat eque estudam em escola agrotechica (a) (a) acordo com os elementos culturais presentes nos grupos. Dessa forma, verificamos formas diferentes de vivenciar a adolescência, corroborando assim, a tendência mais recente que propõe a adolescência como uma condição construída historicamente. Palavras-chave: Psicologia social; representação social; adolescência.
\end{abstract}

To Have and to Be: Social Representations of Adolescence among Adolescentes of Urban and Rural Insertion

Abstract

Based on the Theory of Social Representation the present work analyses how adolescents from different social background Based on the Theory of Social Representation the present work analyses how adolescents from different social background
represent and understand adolescence. Three hundred and sixty adolescents from 14 to 23 years old participated in this research: 180 ( 90 female and 90 male) live in an urban area and study in a private school located in a high-middle class and high class neighborhood, and 180 (90 female and 90 male) live in a rural area and attend an agrotechnical public school.The results pointed out that both groups are anchored on a traditional perception of adolescence as a universal and transitory period. There is, however, a differentiation according to cultural elements present in both groups. Therefore, we observe different forms of experiencing adolescence which confirms the most recent tendency to see adolescence as a historically constructed condition. Keywords: Social psychology; social representation; adolescence.

Até o início do século XX, o conhecimento a respeito do desenvolvimento humano era pouco sistematizado (Oliveira \& Egry, 1997). Entretanto, após este período, vários estudos foram feitos com o objetivo de entender e de tecer teorias sobre o desenvolvimento humano, inclusive acerca do período da adolescência. Vários foram os aspectos abordados, como o físico, o emocional, o cognitivo e o social.

A palavra adolescência é derivada do verbo latino adolescere que significa crescer ou crescer até a maturidade. Enfatizando que a adolescência é um período de transição, Muuss (1976) a considerava um período no qual o indivíduo vive uma situação marginal, na qual novos ajustamentos devem ser feitos entre o comportamento de criança e o comportamento de adulto. Muuss (1976) ainda afirmava que, cronologicamente, a adolescência é o tempo que se estende, aproximadamente, dos 12 ou 13 anos até os 20/21/22 anos, com grandes variações individuais e culturais.

Atualmente, a Organização Mundial da Saúde define os adolescentes como pessoas de 10 a 19 anos e os jovens

Endereço de correspondência: Universidade Federal do Espírito Santo - PPGP, Av. Fernando Ferrari, s/n ${ }^{\circ}$, Goiabeiras, 29060 900, Vitória, ES. E-mail: priscilla.martins@uol.com.br como pessoas de 15 a 24 anos e o termo 'gente jovem' é utilizado para incluir ambos os grupos (OPS - Organización Panamericana de la Salud, 1998, p. 77). Para o Estatuto da Criança e do Adolescente (Lei no 8.069 de 13/07/1990) o adolescente é o indivíduo que se encontra entre a faixa etária de 12 e 18 anos de idade.

À primeira vista, a adolescência se apresenta como uma categoria vinculada à idade, portanto refere-se à biologia, ao estado e à capacidade do corpo; no entanto o desenvolvimento do adolescente não se esgota nas diversas e importantes mudanças que acontecem no âmbito biológico e fisiológico, ele também comporta várias significações superpostas elaboradas sócio-historicamente. Dessa forma, além das mudanças biológicas, também ocorrem mudanças de papéis, de idéias e de atitudes. A Psicologia procurou entender melhor essas mudanças através de estudos, de discussões e de teorizações.

Um dos primeiros estudiosos a respeito foi Stanley Hall. Seu primeiro livro sobre o assunto foi publicado em 1904 sendo, por isso, considerado o pai da "Psicologia da Adolescência" (Muuss, 1976). Hall caracterizou o período da adolescência como uma época de tempestade e de tormenta devido à oscilação entre tendências contraditórias: 
energia, exaltação e superatividade e indiferença, letargia e desprezo. Uma alegria exuberante, gargalhadas e euforia cedem lugar à disforia, depressão e melancolia. O egoísmo, a vaidade e a presunção são tão característicos desse período como o abatimento, humilhação e timidez. (Muuss, 1976, p. 23)

Todavia, ao caracterizar a adolescência como um estágio do desenvolvimento, deixou pouco espaço para as influências do meio. Sendo assim, era natural o adolescente viver uma época conturbada e não havia muita coisa a fazer para mudar essa sua característica, perspectiva essa que se incorporou ao pensamento social orientando as concepções mais tradicionais da adolescência.

Anna Freud aprofundou o estudo desse período a partir da conceituação psicanalítica e atribuiu à adolescência uma grande importância na formação do caráter, partilhando da idéia de que a adolescência é um estágio do desenvolvimento e caracteriza-se como um período turbulento e apontando que pode sofrer influências do ambiente, embora muito pequenas, uma vez que os fatores ambientais, para psicanálise ortodoxa, são secundários em relação aos fatores biológicos e instintivos (Oliveira \& Egry, 1997).

Erick Erikson (1968), utilizando as propostas da psicanálise e os achados da Antropologia Cultural, propõe a Teoria do Estabelecimento da Identidade do Ego, na qua sugere que o ambiente também participa na construção da personalidade do indivíduo. Essa mudança na visão do desenvolvimento é de grande importância, posto que abre novas fronteiras para o entendimento do desenvolvimento e, mais especificamente, da adolescência. De uma forma geral, antes de Erikson, os teóricos concebiam a adolescência como um estágio do desenvolvimento, ou seja, um período universal, como a infância e a idade adulta, com características específicas, constituindo-se em um período necessária e naturalmente conturbado.

Os estudos da Antropologia Social revolucionaram essa forma de pensar a adolescência, mostrando uma possibilidade de entender as fases do desenvolvimento humano de forma totalmente nova, ressaltando duas importantes questões: a adolescência não precisa ser, necessariamente, um período turbulento; as características do desenvolvimento psicossocial não são universais. Na sociedade estudada em Samoa por M. Mead (1967), por exemplo, o desenvolvimento era gradual, calmo e sem impactos profundos.

A questão sobre a universalidade ou não da adolescência é um tema importante e alguns historiadores interessados nesse problema defendem que a adolescência é uma construção social. Oliveira e Egry (1997) fazem um levantamento histórico resgatando o surgimento da Adolescência e afirmam que a adolescência é produto da Revolução Industrial e que pôde ser mais bem observada com a instituição do sistema educacional obrigatório e os programas de maternidade e da infância. Este conjunto de acontecimentos fez com que o período de dependência do indivíduo se estendesse. Dessa maneira, o conceito de adolescência pode ser considerado recente. Acredita-se que o reconhecimento deste como uma etapa do desenvolvimento humano ocorreu no Ocidente no início do século XX (Ariès, 1978). Essa visão sócio-histórica traz mais elementos demonstradores de que a inserção sócio-cultural é fundamental para compreendermos melhor o ser humano.

Através das explicitações das principais teorias sobre a adolescência, podemos observar duas tendências na Psicologia do Desenvolvimento. Uma tendência que propõe a universalidade do estágio da adolescência e uma outra tendência que concebe a adolescência por meio da inserção histórica e cultural, mostrando que este período não necessariamente deverá ser conflituoso, reconhecendo que esta etapa do desenvolvimento envolve a interação do indivíduo com outros e com um contexto. Margulis (2001) propõe, de acordo com essa forma de pensar, utilizar a palavra adolescência no plural, indicando que há mais de uma forma de viver a adolescência. Segundo ela, a adolescência "se trata de una condición historicamente construida y determinada, cuy a caracterización depende de diferentes variables, siendo más notórias la diferenciación social, el genero y la generación" (p. 42).

A adolescência, então, deve ser entendida como um período e um processo psicossociológico de transição entre a infância e a fase adulta e que depende das circunstâncias sociais e históricas para a formação do sujeito. Sendo assim, a adolescência é um período/processo em que o adolescente é convidado a participar, dinamicamente, da construção de um projeto seu, o seu projeto de vida. Neste processo, a identidade, a sexualidade, o grupo de amigos, os valores, a experiência e a experimentação de novos papéis tornam-se importantes nas relações do adolescente com o seu mundo. Nessa fase, o adolescente procura se definir por meio de suas atividades, de suas inclinações, de suas aspirações e de suas relações afetivas.

Apesar dos vários estudos e pesquisas neste campo, o estereótipo de uma adolescência conturbada e de um adolescente rebelde, estabelecido inicialmente por Hall, ainda permeia a sociedade. Podemos dizer que:

o sensacionalismo presente em certos meios de comunicacão generaliza toda a população adolescente, de traços inferidos a partir de certos fatos chamativos de algumas minorias, tais como a exagerada importância atribuída a manifestações superficiais de inconformismo, criando-se estereótipos sobre a tempestade adolescente. Estes podem levar a tornarem-se turbulentos muitos sujeitos, pelo único motivo das expectativas: por ser o que se espera do adolescente e o que se prognostica que vai ser. Assim como em outros âmbitos, a imagem e a expectativa sociais de um fato de conduta 
influem, por sua vez, na incitação e desenvolvimento do mesmo: é a profecia que se autocumpre. (Cárdenas, 2000, p. 22)

Neste estudo, estamos interessados em investigar como os próprios adolescentes significam a adolescência, a partir de uma perspectiva psicossocial.

No âmbito da Psicologia Social, optamos pela Teoria das Representações Sociais ${ }^{2}$ (TRS), dado que:

as representações sociais têm ocupado um espaço importante e têm sido um instrumento fundamental para a compreensão da complexidade, das aparentes discrepâncias e dicotomias que surgem no processo de conhecimento de um dado fenômeno social, tendo como pressuposto fundamental efeito do cotidiano em sua construção. (Trindade, 1996)

Representar, de acordo com esta perspectiva, não significa reproduzir ou duplicar, representar significa mais do que isso, significa re-construir. Em outras palavras, representar é participar ativamente do processo de construção da sociedade e de si. A Teoria das Representações Sociais devolve ao indivíduo a sua importância na formação do social e afirma a sua participação ativa (modifica, movimenta, concorda) e não passiva (meros receptores). Com isso, "el individuo se constitue y constitue sus representaciones tambien constituve su mundo social y construye y reconstruye permanentemente su propia realidad social y su propia identidad personal" (Banchs, 2000, p. 3.10).

Dessa forma:

As Representações Sociais são uma forma de conhecimento, socialmente elaborada e partilhada, tendo uma visão prática e concorrendo para a construção de uma realidade comum a um conjunto social. (Jodelet, citado em Sá, 1993).

Os processos formadores das representações sociai foram descritos como processos de objetivação e de ancoragem. A objetivação tem como função dar materialidade a um objeto abstrato, duplicar um sentido por um objeto e o processo de ancoragem tem a função de dar um sentido inteligível dentro de um contexto. Moscovici, em seu primeiro trabalho sobre a TRS, exemplifica este processo na psicanálise, em que a terapia é uma estranha medicina sem remédios, mas ao mesmo tempo, assemelhada a uma confissão religiosa.

A TRS tem aproximadamente 40 anos. Neste período foi nutrida por vários estudos e pesquisas sobre os mais diversos temas, o que conseguiu refinar a teoria em termos teóricoconceituais, discutir e aperfeiçoar os métodos utilizados e atualizar seus relacionamentos potenciais com outras abordagens do mesmo campo fenomenal. Com esse aprofundamento nos estudos, observamos que a TRS vem possibilitando uma pluralidade metodológica na construção de objetos específicos de pesquisa. Isso ocorreu, também,

${ }^{2}$ A Teoria das Representações surgiu no trabalho de Serge Moscovici intitulado A psychanalyse son image et son public $(1961,1978)$

Psicologia: Reflexão e Crítica, 2003, 16(3), pp. 555-568 devido à resistência de Moscovici em definir com precisão os termos teórico-conceituais, o que parece ter tido como efeito "impedir a cristalização prematura dos conjuntos operacionalizados de conceitos, hipóteses e técnicas de pesquisa que terminassem por constituir 'microteorias' autônomas em relação à grande teoria” (Sá, 1996, p. 8). Essa forma de operacionalizar a TRS permitiu construir abordagens complementares que proporcionam descrições mais detalhadas de certas estruturas, assim como de seu funcionamento, e que se mostram compatíveis com a teoria geral.

Neste estudo, utilizaremos duas dessas abordagens: a Teoria do Núcleo Central, que é desenvolvida em Aix em Provence por Jean Claude Abric e centra-se nos processos sócio-cognitivos com o estudo das estruturas das Representacões Sociais; e a abordagem utilizada por Willem Doise, que é desenvolvida em Genebra, e tem uma ênfase mais sociológica, pois apresenta como objetivo estudar as condições de produção e circulação das Representações Sociais.

Jean Claude Abric, em suas pesquisas, tem tido como objetivo identificar as estruturas representacionais, procurando entender a constituição das representações sociais, o seu conteúdo e estrutura, para compreender, com isso, o seu funcionamento.

Abric propõe que as RS são organizadas em torno de um núcleo central, constituído de um ou mais elementos e que estes elementos organizam e dão significado às RS. Dessa forma, podemos observar que o núcleo central tem duas funções essenciais na estruturação e no funcionamento das RS, são eles:

uma função geradora: ele é o elemento pelo qual se cria, ou se transforma, a significação dos outros elementos constitutivos da representação. É por eles que esses elementos tomam um sentido, um valor [e;] uma função organizadora: é o núcleo central que determina a natureza dos laços que unem entre si os elementos da representação. Ele é nesse sentido o elemento unificador e estabilizador da representação. (Abric, 1998, p. 31)

Além dessas funções, o núcleo central tem a propriedade de estabilidade, isto é, o núcleo central é o elemento mais estável de uma representação social. Essa propriedade assegura a continuidade das RS em contextos móveis e evolutivos. Os elementos do núcleo central são determinados pelas condições históricas, sociológicas e ideológicas e, por isso, são coletivamente partilhados e, portanto, mais resistentes a mudanças.

Em torno do núcleo central e como seu complemento indispensável, organizam-se os elementos periféricos que se constituem como a interface entre a realidade concreta e o sistema central, por isso são mais flexíveis e móveis. Tais elementos possuem três funções primordiais: 1) possibilitam a elaboração das RS e sua utilização em termos concretos, 
compreensíveis e transmissíveis; 2) constituem o aspecto móvel e evolutivo das RS; 3) agem como um elemento de defesa do núcleo central. Dessa forma, em caso de transformações da representação, estas acontecerão primeiramente nos elementos periféricos, pois é no sistem periférico que poderão aparecer e ser toleradas contradições.

A Teoria do Núcleo Central permite-nos identificar, como dito anteriormente, a estrutura e o conteúdo das RS, entretanto observamos que, para tornar este estudo mais completo, seria interessante acrescentar a metodologia utilizada por Willem Doise (2000). O autor utiliza três hipóteses importantes para o estudo das RS:

Uma primeira hipótese é que os diferentes membros de uma população estudada partilham efetivamente certas crenças comuns concernentes a uma dada relação social. As RS se constroem nas relações de comunicação que supõem referentes ou pontos de referência comum aos indivíduos ou grupos implicados nessas trocas simbólicas. Uma segunda hipótese refere-se à natureza das tomadas de posições individuais em relação a um campo de RS. A teoria das RS deve explicar como e porquê os indivíduos diferenciam entre si nas relações que ele mantêm com essa representações. Isto implica que essas variações nas tomadas de posição individuais são organizadas de uma maneira sistemática. Uma terceira hipótese considera a ancoragem das tomadas de posição em outras realidades simbólicas e coletivas, como as hierarquias de valores, as percepç̃es que os indivíduos constroem das relações entre orupos e categorias e as experiências sociais que ele compartilham com o outro. (p. 12)

Através dessas hipóteses, com o objetivo de integrar, em uma mesma análise, os modos de funcionamento d sociedade e do indivíduo, Doise diferencia a sua abordagem. Este autor procura entender não apenas a Representação Social de um grupo, mas como ela ocorre através da ancoragem e como essa ancoragem dá-se de diferentes maneiras permitindo diferentes posições.

Utilizaremos, então, essas duas abordagens neste estudo, pois temos como objetivo compreender a estrutura e o conteúdo das RS, assim como compreender de que forma este tema tratado pelos adolescentes, se existem diferenças dentro desta classe de sujeitos e como estas representações são ancoradas. Dessa forma, o objetivo deste estudo é descrever e analisar os significados da adolescência entre os adolescentes.

\section{Método}

\section{Participantes}

Participaram deste estudo 360 sujeitos entre as idades de 14 e 23 anos que estavam no ensino médio, sendo que 180 (90 do sexo feminino e 90 do sexo masculino) freqüentavam uma escola particular de um bairro de classe média alta e alta em Vitória (ES) e 180 (90 do sexo feminino e 90 do sexo masculino) freqüentavam uma escola pública de uma região eminentemente agrícola deste mesmo Estado. Esta é uma escola agrotécnica federal que, ao final do curso, permite aos estudantes trabalharem em conformidade com o CREA - Conselho Regional de Engenharia, Arquitetura e Agronomia, elaborando e acompanhando os projetos dentro da área de agropecuária. Por suas características, a escola recebe, em sua maioria, alunos vinculados a atividades rurais.

\section{Procedimento de Coleta de Dados e Instrumento}

Foi aplicado em sala de aula, de forma coletiva, com o consentimento da direção da escola, um questionário dividido em três partes. Para este artigo avaliaremos a primeira e a segunda partes. A primeira parte consta de dados pessoais e a segunda tem como objetivo investigar o que os participantes pensam a respeito da adolescência. As perguntas sobre a adolescência foram elaboradas com uma questão utilizando a técnica de associação livre e duas questões utilizando perguntas abertas A associação livre é uma técnica utilizada por Abric que consegue coletar os elementos constitutivos do conteúdo de uma representação. De acordo com ele esse método é vantajoso, pois tem um "caráter espontâneo - portanto menos controlado - e a dimensão projetiva dessa produção deveria, portanto permitir o acesso, muito mais facilmente e rapidamente do que uma entrevista aos elementos que constituem o universo semântico do termo ou do objeto estudado". (Abric, 2001, p. 66)

O termo indutor utilizado para a associação livre foi adolescente. As perguntas abertas foram: $\mathrm{O}$ que você considera importante para se ter uma vida feliz? E, de acordo com a sua opinião, quais são as preocupações do adolescente e do jovem de hoje?

\section{Procedimento de Análise dos Dados}

A análise dos dados foi feita por meio de três softwares: o Alceste (Analyse Lexicale par Contexte d'um Ensemble de Segments de Texte), o Evoc (Ensemble de Programmes Permettant L'Analyse dês Évocations) e o SIMI. O programa Alceste foi utilizado na análise das respostas das questões abertas que foram elaboradas com o objetivo de abranger os aspectos pertencentes à vida dos adolescentes. O EVOC e o SIMI foram utilizados na análise das evocações da questão em que foi utilizada a associação livre.

O programa Alceste analisa o corpus que é o objeto de estudo do pesquisador, ou seja, aquilo que é de interesse de pesquisa, um texto transcrito (entrevista, grupo focal, narrativas orais, entre outros) ou já escrito (livro, capítulo de livro, artigo de revista, entre outros). O corpus preparado é caracterizado por seus aspectos relevantes como idade, sexo, profissão. A análise estatística efetuada pelo Alceste no corpus consiste em uma Classificação Hierárquica Descendente (CHD), para isso primeiramente o programa efetua uma matriz palavra por unidade contextual (afirmações) com o objetivo de investigar semelhanças e dessemelhanças estatísticas das palavras visando identificar padrões repetitivos de linguagem. 
O conjunto das unidades contextuais na matriz de indicadores inicial constitui a primeira classe. O objetivo da $\mathrm{CDH}$ é conseguir uma divisão dessa classe em duas, da maneira mais nítida possível, de tal forma que as duas classes não contenham palavras sobrepostas. "Tecnicamente, isso consiste na decomposição da matriz em duas classes através de um escalonamento otimizado e interrompendo o conjunto ordenado de palavras quando um critério, baseado em determinado valor de $\mathrm{x}^{2}$, alcançar um ponto máximo" (Wagner \& Kronberger, 2002, p. 429). Isso ocorre quantas vezes for necessário, decompondo assim uma classe em várias classes. A CDH também apresenta a posição de cada classe sob forma de uma árvore (dendograma). O dendograma possibilita verificar a ligação entre as classes (forte ou fraca) e a representatividade de cada classe (em percentil) dentro do corpus avaliado. O programa, também, efetua uma Análise Fatorial de Correspondência (AFC) que permite a visualização das posições das classes resultantes da $\mathrm{CDH}$ e das posições das variáveis, por meio do plano fatorial. Por meio desse plano é possível verificar uma relação entre variáveis e classes. Para maiores detalhes sobre o programa o leitor pode consultar Wagner e Kronberger (2002).

Este programa analisa as palavras evocadas em função de dois critérios, a freqüência e a ordem de evocação. A combinação desses dois critérios permite o levantamento daqueles elementos que mais provavelmente se associam ao termo indutor e, conseqüentemente, também permite o levantamento da organização interna das representações sociais associadas a esses termos. Os resultados são organizados em quatro quadrantes: no primeiro quadrante situam-se os elementos mais relevantes e, por isso, possíveis de consituirem o núcleo central. Estes elementos são os mais prontamente evocados e citados com uma freqüência elevada. $\mathrm{O}$ segundo e terceiro quadrantes correspondem aos elementos menos salientes na estrutura da representação, contudo são significativos em sua organização. No segundo quadrante estão os elementos que obtiveram uma freqüência alta, mas que foram citados nas últimas posições e; no terceiro quadrante encontram-se os elementos que foram citados com uma freqüência baixa, porém foram evocados primeiramente. No quarto quadrante estão os elementos que correspondem à periferia distante ou segunda periferia. Neste quadrante estão os elementos menos citados e menos prontamente evocados (Ribeiro, 2000).

O SIMI realiza uma nova análise, utilizando o resultado da análise das evocações, chamada de Análise de Similitude. A análise de similitude foi introduzida no campo das representações sociais por Claude Flament, com a participação de Vergés e Degenne nos anos 1970, mesma ocasião da configuração da Teoria do Núcleo Central. Com isso, a análise de similitude tornou-se a principal técnica de detecção do grau de conexidade dos diversos elementos de uma representação (Sá, 1996). Para a análise de similitude, primeiramente os dados são organizados em categorias. Depois de feito isso, realiza-se, então, a análise de similitude entre as categorias. Esta análise permite visualizar, através de um gráfico chamado árvore máxima, se há relação entre as categorias e se esta relação é forte ou fraca. As relações são representadas por quatro classes, são elas: linha pontilhada, linha simples, linha dupla e linha tripla, sendo a linha pontilhada a relação mais fraca e a linha tripla a mais forte. Existem três tipos diferentes de configuração para a árvore máxima: “a estrela, em torno de uma noção que se liga a muitas outras; o triângulo, que liga três noções duas a duas; e o ciclo, que liga mais de três noções” (Sá, 1996, p. 130). A estrela é, obviamente, a estrutura que evidencia de forma mais flagrante a existência de um elemento organizador, central, ou mesmo mais de um.

\section{Resultados}

Para efeito de clareza utilizaremos a nomenclatura de sujeito da zona urbana para os participantes que freqüentam a escola localizada na capital (Vitória) e a de participantes da zona rural para os participantes que freqüentam a escola localizada na zona rural.

Os participantes da zona urbana que participaram desse estudo encontram-se na faixa etária de 14 a 19 anos e os da zona rural na faixa etária de 14 a 23 anos.

Sobre a escolaridade paterna observamos que a maioria dos pais dos participantes da zona urbana $(75,55 \%)$ possui o ensino superior completo; $16,11 \%$ têm o ensino médio completo e; 6,11\% o ensino fundamental completo. Entre os pais dos participantes da zona rural encontramos uma situação bem diferente: $33,33 \%$ não concluíram o ensino fundamental; $24,44 \%$ têm o ensino fundamental completo; $24,44 \%$ têm o ensino médio completo e apenas $5 \%$ possuem o ensino superior.

Ao compararmos a escolaridade materna entre esses dois grupos observamos que $64,44 \%$ das mães dos participantes da zona urbana e que $24,44 \%$ das mães dos participantes da zona rural têm o ensino superior. O número de mães com o ensino médio completo é parecido para os dois grupos (27,77\% são mães dos participantes da zona urbana e 25,55\% são mães dos participantes da zona rural). Apenas as mães dos participantes da zona rural responderam não ter concluído o ensino fundamental, sendo que a maior freqüência de respostas para esses participantes encontrase neste nível de escolaridade (29,44\%).

Os dados não mostram grandes diferenças entre os dois grupos em relação à situação profissional paterna, pois a expressiva maioria dos pais encontra-se trabalhando no momento $(93,88 \%$ m, para os pais dos participantes da zona urbana; e, $81,11 \%$, para os pais dos participantes da zona rural). Entretanto, existem diferenças entre os dois grupos em relação à situação profissional materna em que 76,11\% 
das mães dos participantes da zona urbana e 55\% das mães dos participantes da zona rural estão no mercado de trabalho e 16,11\% das ma es dos participantes da zona urbana têm como função os serviços domésticos com 38,33\% das mães do outro grupo, exercendo a mesma atividade.

Os resultados seguintes serão apresentados utilizando a metodologia de Doise. Primeiramente, será apresentada a análise de todos os participantes, visando à explicitação do campo comum das RS dos participantes. Posteriormente, a análise dos dados será apresentada considerando os grupos em separado, para podermos reconhecer as diferenças existentes entre as posiçoes de cada grupo. Por último, na seção Discussão, será apresentada a ancoragem das RS. Procuramos demonstrar que a tomada de posição ocorre de acordo com um sistema de representações no qual se incluem crenças, avaliações e normas sociais

Primeiro Nível: O Campo Comum das Representações Sociais de Adolescência

Análise das Questões Abertas pelo ALCESTE

A análise correspondente às questões sobre adolescência apresentou cinco classes. A Figura 1 demonstra essas classes e a relação existente entre elas.

\begin{tabular}{|c|c|c|c|c|}
\hline \multicolumn{4}{|c|}{$\mathrm{R}=0$} & \\
\hline \multicolumn{2}{|c|}{$\mathrm{R}=0,35$} & \multicolumn{2}{|r|}{$\mathrm{R}=0,65$} & $\mathrm{R}=0,65$ \\
\hline Classe 1 & \multirow{2}{*}{$\begin{array}{l}\text { Classe } 2 \\
\text { Seguir o } \\
\text { caminho certo }\end{array}$} & Classe 5 & \multirow{2}{*}{$\frac{\text { Classe } 3}{\text { Ter um futuro }}$} & Classe 4 \\
\hline Curtição & & $\begin{array}{l}\text { Amar e ser } \\
\text { amado }\end{array}$ & & $\begin{array}{l}\text { É preciso ter apoio e cui- } \\
\text { dado com o hoje para ter } \\
\text { um bom futuro }\end{array}$ \\
\hline $\begin{array}{l}\text { Adolescente } \\
\text { Acho } \\
\text { Ele } \\
\text { Estão } \\
\text { Hoje } \\
\text { Jovens } \\
\text { Muito } \\
\text { Outro } \\
\text { Preocupar } \\
\text { Querem } \\
\text { Maioria } \\
\text { Só } \\
\text { Tem } \\
\text { Curtir }\end{array}$ & \begin{tabular}{|l|} 
Problema \\
Acreditar \\
Alguém \\
Algum \\
Caminho \\
Consigo \\
Escola \\
Feliz \\
Mesmo \\
Meu \\
Nunca \\
Objetivos \\
Pode \\
Procurar \\
Sempre \\
Sonho \\
Tentar \\
\end{tabular} & $\begin{array}{l}\text { Base } \\
\text { Amado } \\
\text { Amar } \\
\text { Antes } \\
\text { Ao } \\
\text { Conviver } \\
\text { Diversão } \\
\text { Entendimento } \\
\text { Faz } \\
\text { Humildade } \\
\text { Imagem } \\
\text { Inimigos } \\
\text { Principalmente } \\
\text { Próximo } \\
\text { Ser } \\
\text { Todas }\end{array}$ & $\begin{array}{l}\text { Bom } \\
\text { Boa } \\
\text { Conseguir } \\
\text { Depois } \\
\text { Emprego } \\
\text { Entrar } \\
\text { Faculdade } \\
\text { Família } \\
\text { Harmonia } \\
\text { Relacionamento } \\
\text { Ter } \\
\text { Um } \\
\text { Uma } \\
\text { Unida } \\
\text { Vestibular } \\
\text { Viver }\end{array}$ & $\begin{array}{l}\text { Divertir } \\
\text { Bebida } \\
\text { Camisinha } \\
\text { Doença } \\
\text { Droga } \\
\text { Engravidar } \\
\text { Filho } \\
\text { Namorado } \\
\text { Saúde } \\
\text { Sexo } \\
\text { Sexualmente } \\
\text { Transmissíveis } \\
\text { Usar } \\
\text { Violência }\end{array}$ \\
\hline $40,89 \%$ & $17,18 \%$ & $8,93 \%$ & $8,93 \%$ & $9,97 \%$ \\
\hline \begin{tabular}{l|l} 
& \\
Curtição
\end{tabular} & $\frac{1}{\text { Busca c }}$ & \begin{tabular}{|l|l} 
& \\
Felicidade
\end{tabular} & & \\
\hline
\end{tabular}

Figura 1. Estrutura do corpus das questões abertas sobre a adolescência $(n=360)$.

A expressão rockéutilizada pelos adolescentes e jovens com o significado de diversão, curtição, acontecimento. Ex.: Qual vai ser o rock hoje? Significa: Qual vai ser a curtição hoje? Qual vai ser o acontecimento hoje?

Como apresenta a Figura 1, a análise das questões abertas sobre adolescência indicou três grandes eixos na organização da RS sobre a adolescência: Curticão, Busca da Felicidade e Futuro. Observamos que existe uma forte relação entre as classes 2 e $5(r=0,75)$ e entre as classes 3 e $4(r=0,65)$. A classe 1 corresponde a um eixo que tem uma relação, ainda que mais fraca $(r=0,35)$ com o eixo Busca da Felicidade.

O primeiro eixo (Curtição) corresponde ao discurso de que $\mathrm{o}$ adolescente e o jovem estão preocupados apenas com o presente e não com o seu futuro em relação ao trabalho e ao estudo. Esse presente significa estar com os amigos e divertir-se, significa saber qual vai ser o rock ${ }^{3}$ do dia. Esse discurso está muito vinculado ao estereótipo de adolescente rebelde e confuso e que não consegue diferenciar entre o certo e o errado e, por isso, muitas vezes segue o caminho errado. É interessante ressaltar que a maioria das falas emitidas $(40,89 \%)$ está configurada nesta classe. Abaixo seguem algumas falas encontradas nos questionários respondidos pelos participantes.

"Muitos adolescentes não querem saber de escola, querem apenas sair à noite".

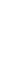


"Os jovens e adolescentes de hoje estão muito divididos, alguns estão pensando no seu futuro, mas a maioria só quer saber de curtição".

"Muitos adolescentes se preocupam em curtir uma balada chocante, e o que é chocante? São bebidas, cigarros, pensam em ficar ${ }^{4}$ com muitos sem se preocupar com os riscos".

O segundo eixo corresponde à preocupação em ser feliz e de como alcançar essa felicidade. O discurso dos participantes indica-nos que existem, para eles, duas formas de alcançar esse objetivo. A classe 2 representa o discurso de seguir o caminho certo, ou seja, é preciso para isso gostar de si, gostar dos outros, acreditar e ter força de vontade para alcançar os seus objetivos.

"Ter bons e verdadeiros amigos, ter pessoas que gostem de mim, me sair bem no que faço, realizar meus sonhos, correr atrás dos meus objetivos".

"Ter fé em Deus e esquecer das coisas ruins, tentar praticar sempre o bem, acreditar em si próprio e não o que vem dos outros".

"Uma família amorosa, uma vida estruturada, boa aceitação no meio que vive, bom desempenho na escola e trabalho e bons amigos".

A classe 5 Amar e ser amado apresenta que a questão do reconhecimento do adolescente como pessoa é de grande importância para o alcance da felicidade. Para esses participantes, o reconhecimento significa também amor. Amor que só é obtido caso consiga amar.

“Acreditar em Deus, ter apoio para se sentir seguro, não necessariamente da família e se possível amar e ser amado. Buscar ser humilde também".

"Principalmente se sentir amado, pois se a pessoa não sente isso, ela começa a afundar na vida".

"Não ir pela idéias de ninguém como entrar na vida de violência, drogas, etc. Ser simpática com as pessoas e amar o próximo".

Nesse eixo há, também, a presença do discurso da religião. Isso pode ser observado pelo modo como lidam com a vida: é preciso amar ao próximo como a ti mesmo e a Deus acima de todas as coisas (Novo Testamento). Além disso, observamos a necessidade de alguns adolescentes em sustentar a sua vida em torno da fé na religião, visto que é por meio dela que conseguem as forças necessárias para poder seguir no caminho certo e também é por meio dela que conseguem ser amados.

O terceiro eixo refere-se à preocupação que os adolescentes mantêm com o Futuro. A classe 3 apresenta

${ }^{4} \mathrm{O}$ verbo ficar é utilizado como sinônimo de um namoro rápido, em que em um período curto, que pode ser o tempo de duração de uma festa ou de um show por exemplo, é permitido comportar-se como namorada e namorado. O limi de intimidade é determinado pelos envolvidos. seu discurso organizado em torno da preocupação em ter um futuro, ou seja, em ter um bom emprego, em conseguir entrar em uma faculdade, ter uma família e viver em harmonia. Abaixo estão algumas falas desses adolescentes.

"Viver em paz com a vida e com todos em geral, viver em harmonia e ter senso de humor. Passar no vestibular, entrar
numa faculdade, iniciando uma vida adulta e a partir daí se tornar independente e mais responsável".

"Ter família, boa educação, bons estudos, bom emprego e fazer aquilo que gosta. Conseguir passar no vestibular, recursos para pagar uma faculdade e conseguir emprego". "Ter Jesus no coração em primeiro lugar. Preocupações de não conseguir, no futuro, ter um emprego adequado".

A classe 4 foi nomeada É preciso ter apoio e cuidado com o hoje para ter um bom futuro, e corresponde justamente às preocupações que o adolescente confere ao presente, posto que o presente está cercado de problemas e de caminhos errados como: drogas, gravidez indesejada, doenças sexualmente transmissíveis e violência. Nesse sentido, o adolescente precisa ter cuidado e, mais do que isso, necessita do apoio das pessoas que o cercam para poder seguir o caminho certo. Sendo assim, de acordo com as palavras dos participantes, as preocupações são:

"Ter saúde, educação, bons pais e boas companhias, segurança, etc. As doenças sexualmente transmissíveis, escolha do futuro, profissão, estudos, violência, etc".

"Um ambiente familiar bom, calmo, uma educação boa. O sexo sem camisinha, drogas, violência, a preocupação quando se tem muita liberdade".

"A violência e a facilidade de usar drogas, também as doenças transmitidas sexualmente e a possível geração de um filho em uma relação irresponsável”.

Análise das Questões de Evocação pelo EVOC

Primeiramente, será apresentado, na Tabela 1 , o resultado das questões de evocação analisado pelo EVOC com o objetivo de fazer o levantamento da organização interna das representações. Os resultados serão apresentados em uma tabela de quatro quadrantes organizados em dois eixos. O eixo vertical corresponde à freqüência de evocação das palavras e o eixo horizontal à ordem de evocação.

A partir da análise das evocações podemos observar na Tabela 1 que os possíveis elementos que organizam a RS de adolescência são: alegria, descobertas, liberdade, problemas e responsabilidade. Esse resultado mostra-nos que o adolescente enxerga a adolescência como um período de descobertas, de maior liberdade, mas também um período em que existem problemas que precisam ser resolvidos. Nesse período, também aumenta a responsabilidade devido a esses outros elementos citados. A alegria, como elemento mais freqüente e com a maior média de evocação, é um elemento importante na configuração da RS de adolescência. 
Tabela 1

Elementos da Representação dos Sujeitos sobre a Adolescência, em Função da Freqüência e Ordem Média de Evocação (n=360)

\begin{tabular}{|c|c|c|c|c|c|}
\hline & & \multicolumn{4}{|c|}{ Ordem média de evocação } \\
\hline & & \multicolumn{2}{|l|}{ Inferior a 2,8} & \multicolumn{2}{|c|}{ Superior a 2,8} \\
\hline & Acima ou & 47 - Alegria & 2,74 & 46 - Amizade & 3,45 \\
\hline & igual a 31 & 35 - Descobertas & 2,68 & 51 - Diversão & 3,02 \\
\hline $\mathrm{F}$ & evocações & 41 - Liberdade & 2,36 & 44 - Drogas & 2,86 \\
\hline $\mathrm{R}$ & & 31 - Problemas & 2,67 & 36 - Estudo & 3,19 \\
\hline $\mathrm{E}$ & & 46 - Responsabilidade & 2,76 & 48 - Festas & 3,16 \\
\hline Q & & & & 45 - Namoro & 3,64 \\
\hline$\ddot{\mathrm{U}}$ & & & & $54-$ Sexo & 3,31 \\
\hline$\hat{\mathrm{E}}$ & Abaixo & 20 - Amadurecimento & 2,60 & 26-Amor & 3,96 \\
\hline $\mathrm{N}$ & de 31 & 16 - Complicado & 2,06 & 12 - Bagunça & 3,08 \\
\hline C & evocações & 13 - Fase & 2,30 & 18 - Curiosidade & 3,50 \\
\hline I & & 24 - Felicidade & 2,54 & 20 - Curtição & 2,90 \\
\hline A & & 12 - Imaturidade & 1,91 & 21 - Dúvidas & 3,04 \\
\hline & & 28 - Irresponsabilidade & 2,67 & 24 - Futuro & 3,16 \\
\hline & & 21 - Juventude & 2,28 & 13 - Mulher & 3,30 \\
\hline & & 27 - Mudança & 2,33 & 17 - Preocupação & 4,05 \\
\hline & & 29 - Rebeldia & 2,17 & 16 - Rock & 3,18 \\
\hline & & 23 - Vida & 2,73 & & \\
\hline
\end{tabular}

$\mathrm{N}^{\text {o }}$ total de evocações $=1719$

$\mathrm{N}^{\circ}$ total de palavras diferentes $=414$

Tabela 2

Relação das Categorias e Exemplos de Palauras Relacionadas às Categorias

\begin{tabular}{ll}
\hline Categorias & Exemplo de palavras relacionadas às categorias \\
\hline $\begin{array}{l}\text { Saúde } \\
\text { Liberdade }\end{array}$ & $\begin{array}{l}\text { Academia, conhecer seu corpo, cuidados. } \\
\text { Curtição }\end{array}$ \\
Desejo de liberdade, liberal, liberdade, livre. \\
Lazer, alegria, diversão, sair, noite, ficar, rock, risadas. \\
Malandro, mal-educado, vandalismo, violência, intolerantes, indisciplinado, \\
Futuro & Faculdade, esperança, expectativa, emprego, profissão, procura de objetivos, sonhos. \\
Transição & Fase, fase de crescimento, transformação, transição. \\
Relacionamento afetivo & Relacionamento, sexo, namoro, mulher-homem, amor, amizade, família. \\
Fase difícil & Aborrecimento, complicado, dificuldades, problemas, conflito, confuso. \\
Fase boa & Fase boa, melhor fase, nunca devia acabar, pena que passa. \\
Atributos positivos & Bom, capaz, caráter, coragem, disposição, esperto, responsabilidade. \\
\hline
\end{tabular}

Ela nos aponta para um adolescente feliz, para um adolescente sempre disposto a participar com os amigos de brincadeiras e de festas, para um adolescente um tanto quanto agitado e que está sempre em busca de algo para divertir-se.

Para a realização da análise de similitude entre os elementos evocados pelos adolescentes, foi necessário, primeiro, organizar estes elementos em categorias de forma que todos pudessem ser colocados em uma das categorias e que um mesmo elemento só pudesse pertencer a uma categoria. As categorias encontradas encontram-se na Tabela 2
A partir do resultado obtido, pudemos fazer a análise de similitude entre as categorias. Na Figura 2, verificamos dois eixos que estão conectados, o eixo Curtição e o eixo Transição. Podemos observar que o primeiro eixo está relacionado com mais força à Delinqüência e Futuro (linha tripla), seguido de Atributos Positivos (linha dupla), Relacionamento Afetivo (linha simples) e Fase Boa (linha pontilhada). A categoria Saúde está relacionada à categoria Relacionamento Afetivo com pouca força (linha pontilhada). Esta configuração apresenta-se em concordância com a análise pelo ALCESTE das questões 


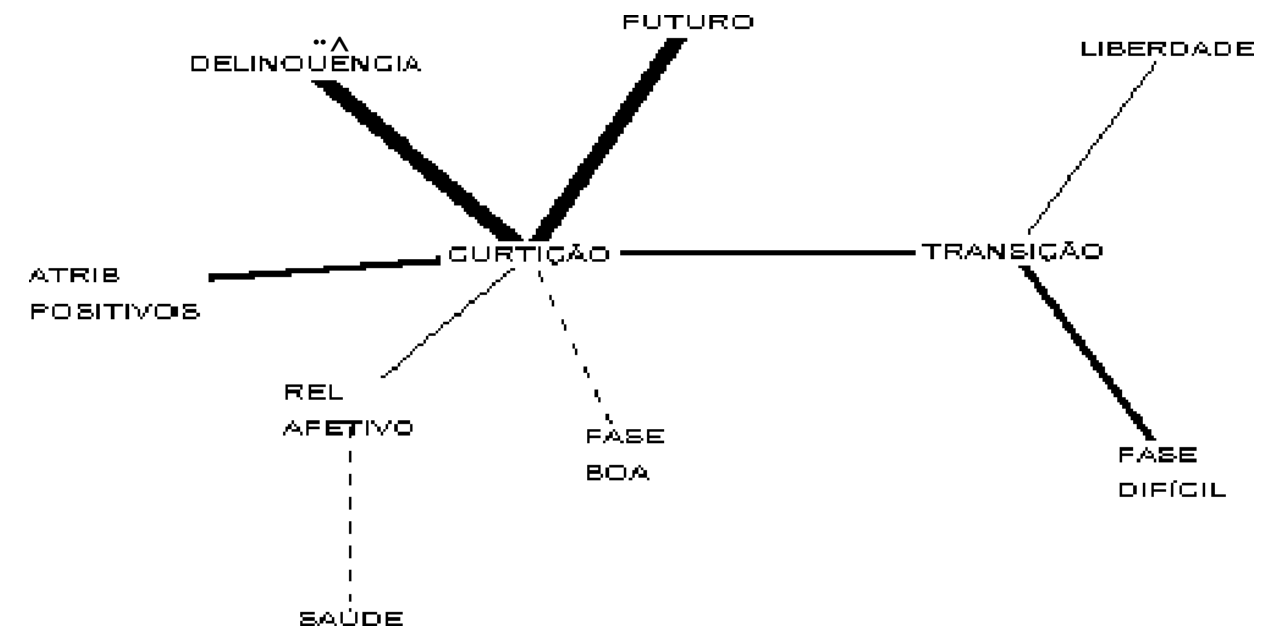

Figura 2. Gráfico de análise de similitude das categorias relacionadas à adolescência $(n=360)$.

abertas. Podemos observar que a Curticão é parte importante do ser adolescente, ela corresponde aos Relacionamentos Afetivos (namoro, ficar, estar com amigos) e é uma Fase Boa. No entanto, o adolescente precisa ser responsável e ter bom caráter para que a Curticão não o leve a perder-se na Delinquieencia.

O outro eixo que este gráfico mostra indica uma visão mais estereotipada do adolescente. Este se encontra em uma fase de Transição para uma Liberdade maior e esta transição é algo Difícil, relembrando a definição de Hall para a adolescência de Tempestade e Tormenta.

\section{Segundo Nível: Diferenciações Grupais}

Este nível de análise permite a verificacão da existência de diferenças na organização das RS dos adolescentes sobre a adolescência. Utilizamos a análise fatorial de correspondência para verificar se existem diferenças entre os grupos e, posteriormente, analisaremos as palavras das questões de evocação de acordo com essa diferença.

Análise Fatorial de Correspondência Realizada pelo ALCESTE

A análise fatorial de correspondência permite cruzar as classes encontradas com as variáveis pesquisadas, indicando uma relação entre variável e classe. Neste estudo as variáveis analisadas foram sexo, localidade de moradia, situação civil parental, escolaridade parental e situação profissional parental. A variável de maior significância e ao redor da qual se agrupam discursos distintos é a variável localidade de moradia.

Por meio da Análise Fatorial verificamos que existem dois discursos diferentes, um mais relacionado aos adolescentes que residem na zona urbana e outro relacionado aos adolescentes que residem na zona rural. O discurso dos primeiros apresentam maior expressividade na classe Curticão e É preciso ter apoio e cuidado com o hoje para ter um bom futuro. Dessa forma, esses adolescentes têm maior possibilidade de vivenciar a curtição, namorar, divertir-se, ir a festas, sair com amigos, entretanto a curtição possui alguns perigos como a gravidez precoce, as drogas, as doenças sexualmente transmissíveis. São, justamente, esses os perigos com os quais se deve tomar cuidado; caso contrário, o adolescente pode prejudicar o futuro por ele idealizado. Contudo, o cuidado em si não é suficiente, é necessário também o conselho e o apoio de pessoas mais experientes, como os pais, ou de importância afetiva, como os amigos, para passar as experiências vividas.

O discurso dos adolescentes que residem na zona rural está mais relacionado às classes Seguir o caminho certo, Amar e ser amado e Ter um futuro. A partir disso, podemos dizer que esses adolescentes têm como objetivo um bom futuro; mas para alcançar tal objetivo, precisam ser bons, responsáveis, trabalhadores, humildes, além de amar e serem amados. Para esses adolescentes, as regras são claras e por isso eles têm bem definido o qual é o caminho certo e o caminho errado para alcançar o seu objetivo.

Análise das Palauras de Evocação de acordo com a Localidade de Moradia

A análise anterior permitiu verificar que a variável relevante para a construção da RS de adolescência é o local de moradia; a partir disso, realizamos a análise das questões de evocação de acordo com este parâmetro.

\section{1) Adolescentes da Zona Urbana}

A partir da associação livre dos adolescentes da zona urbana, como mostra a Tabela 3, surgem os seguintes elementos que provavelmente constituem o núcleo central da RS de adolescência: alegria, juventude, liberdade, problemas. Estes elementos e os elementos da periferia corroboram, de certa forma, a análise fatorial, posto que as palavras mais citadas são sobre alegria, curtição, festas, liberdade, porém também são sobre problemas, complicação e drogas.

Para a realização da análise de similitude, os dados coletados indicaram as mesmas categorias que as utilizadas 
Tabela 3

Elementos da Representação dos Sujeitos da Capital sobre a Adolescência, em Função da Freqüência e da Ordem Média de Evocação $(n=180)$

\begin{tabular}{|c|c|c|c|c|c|}
\hline & & \multicolumn{4}{|c|}{ Ordem média de evocação } \\
\hline & & \multicolumn{2}{|l|}{ Inferior a 2,7} & \multicolumn{2}{|l|}{ Superior a 2,7} \\
\hline & Acima ou & 27 - Alegria & 2,66 & 29 - Amizade & 3,20 \\
\hline & igual a 16 & 19 - Juventude & 2,21 & 17 - Descobertas & 2,76 \\
\hline & evocações & 23 - Liberdade & 2,43 & 32 - Diversão & 3,09 \\
\hline & & 20 - Problemas & 2,65 & 24 - Drogas & 2,91 \\
\hline & & & & 18 - Estudo & 3,22 \\
\hline & & & & 33 - Festas & 3,00 \\
\hline $\mathrm{F}$ & & & & 22 - Namoro & 3,86 \\
\hline $\mathrm{R}$ & & & & 26 - Responsabilidade & 2,88 \\
\hline $\mathrm{E}$ & Abaixo & 08-Complicado & 1,62 & $35-$ Sexo & 3,05 \\
\hline Q & de 16 & 14 - Felicidade & 2,35 & 09 - Amadurecimento & 3,44 \\
\hline$\stackrel{\ddot{U}}{\hat{n}}$ & evocações & 15 - Rebeldia & 2,20 & 15 - Amor & 4,40 \\
\hline$\hat{\mathrm{E}}$ & & 15 - Vida & 2,40 & 09 - Conflito & 2,88 \\
\hline $\mathrm{N}$ & & & & 10 - Curiosidade & 4,20 \\
\hline $\mathrm{C}$ & & & & 13 - Curtição & 3,07 \\
\hline $\mathrm{I}$ & & & & 09 - Escola & 3,88 \\
\hline A & & & & 10 - Irresponsabilidade & 2,80 \\
\hline & & & & 14 - Mudanças & 2,71 \\
\hline & & & & 09- Mulher & 3,22 \\
\hline & & & & 13 - Rock & 3,23 \\
\hline
\end{tabular}

para análise do grupo inteiro: Saúde, Liberdade, Curtição, Delinqüêencia, Futuro, Transição, Relacionamento Afetivo, Fase Dificill, Fase Boa, Atributos Positivos.

O resultado da análise de similitude desses participantes apresenta-se diferente da análise feita com todos os participantes. Ao observarmos a Figura 3 não vemos uma configuração de estrela como a anterior, vemos um ciclo com quatro categorias ligadas duas a duas. De acordo com a relação existente entre elas podemos verificar três eixos nos quais todos têm a categoria Liberdade como idéia comum. A categoria L iberdade está conectada às demais por uma linha dupla. Observamos que a Curticão em

uma relação mais fraca (linha simples) também mantém relações em todos os eixos.

No primeiro eixo Liberdade-Transição, constatamos a mesma lógica que no segundo eixo da Figura 2, isto é, a imagem estereotipada de adolescência de ser uma fase tumultuada e difícil. No segundo eixo Liberdade-Curtição também observamos a mesma lógica que no primeiro eixo da Tabela 2; todavia, a esse sentido soma-se a categoria $L$ iberdade. $\mathrm{O}$ terceiro eixo LiberdadeRelacionamento Afetivo demonstra-nos a importância que o relacionamento com pessoas significantes tem para esses participantes, chegando mesmo a estar relacionado com a Saúde.

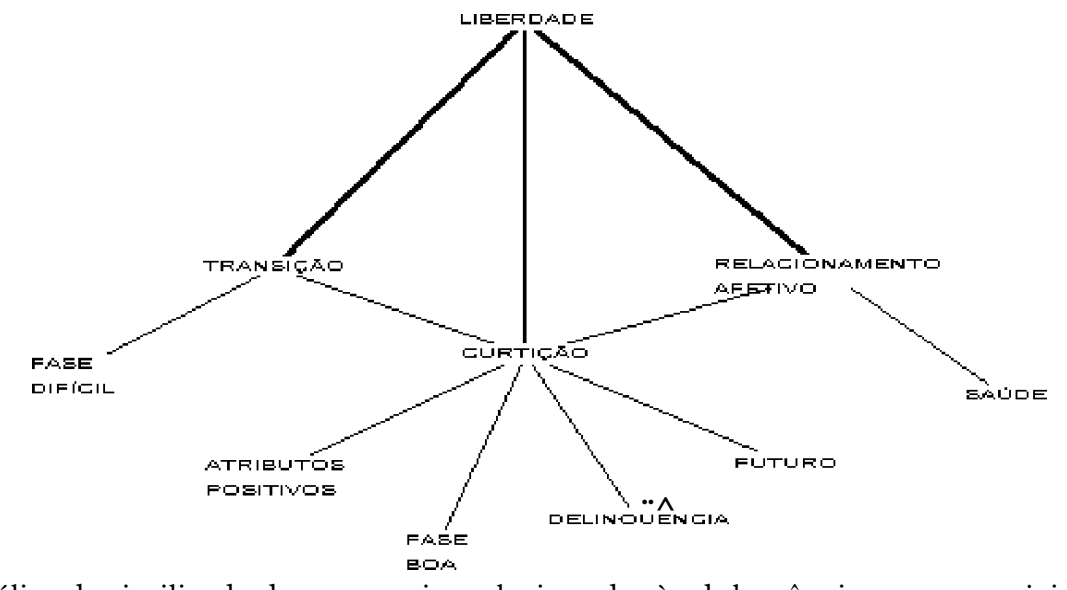

Figura 3. Gráfico de análise de similitude das categorias relacionadas à adolescência entre os sujeitos da capital $(n=180)$. 
2) Adolescentes da zona rural

$\mathrm{Na}$ Tabela 4, observamos os resultados da análise das evocações dos participantes que apresentam os seguintes elementos que provavelmente constituem o núcleo central da RS de adolescência: alegria, liberdade, rebeldia, responsabilidade. Para este grupo observamos que, além da alegria e da liberdade, aparecem as palavras responsabilidade e rebeldia com uma freqüência e uma ordem de evocação alta. O que nos esclarece que para esses participantes a adolescência também é um período de responsabilidades e não apenas de curtição. A palavra rebeldia aparece e contrapõe-se a palavra responsabilidade, visto que caracteriza o adolescente como um indivíduo que precisa ser "domado" para assumir as suas responsabilidades e, futuramente tornar-se um adulto.

Para a realização da análise de similitude, foram utilizadas as mesmas categorias utilizadas anteriormente.

Tabela 4

Elementos da Representação dos Sujeitos do Interior sobre a Adolescência, em Função da Frequiência e da Ordem Média de Evocação (n=180)

\begin{tabular}{|c|c|c|c|c|c|}
\hline & & \multicolumn{4}{|c|}{ Ordem média de evocação } \\
\hline & & \multicolumn{2}{|l|}{ Inferior a 2,9} & \multicolumn{2}{|l|}{ Superior a 2,9} \\
\hline \multirow{5}{*}{$\mathrm{F}$} & Acima ou & 25 - Alegria & 2,88 & 25 - Drogas & 3,00 \\
\hline & igual a 19 & 14 - Liberdade & 2,08 & 19 - Estudo & 3,36 \\
\hline & evocações & 20 - Rebeldia & 2,35 & 22 - Festas & 3,36 \\
\hline & & 25 - Responsabilidade & 2,84 & 23 - Namoro & 3,78 \\
\hline & & & & $33-$ Sexo & 3,06 \\
\hline $\mathrm{R}$ & Abaixo & 12 - Amadurecimento & 2,50 & 18 - Amizade & 3,88 \\
\hline $\mathrm{E}$ & de 19 & 09 - Complicado & 2,11 & $11-$ Amor & 4,63 \\
\hline Q & evocações & 18 - Diversão & 2,61 & 09 - Curiosidade & 3,33 \\
\hline U & & 11 - Dúvida & 2,63 & 12 - Curtição & 2,91 \\
\hline E & & 07 - Fase & 1,71 & 10 - Descobertas & 3,40 \\
\hline $\mathrm{N}$ & & 12 - Felicidade & 2,50 & 07 - Esporte & 5,28 \\
\hline C & & 06 - Indecisão & 2,66 & 11 - Futuro & 3,18 \\
\hline 1 & & 06 - Insegurança & 2,66 & 17 - Irresponsabilidade & 3,00 \\
\hline A & & 14 - Juventude & 2,14 & 08 - Preocupação & 3,62 \\
\hline & & 07 - Medo & 2,57 & & \\
\hline & & 14 - Mudança & 2,21 & & \\
\hline & & 08 - Mulher & 2,87 & & \\
\hline & & 15 - Problemas & 2,40 & & \\
\hline & & 10 - Rock & 2,50 & & \\
\hline & & 13 - Vida & 2,53 & & \\
\hline
\end{tabular}

$\mathrm{N}^{\mathrm{o}}$ total de evocações $=860 \quad \mathrm{~N}^{\mathrm{o}}$ total de palavras diferentes $=292$

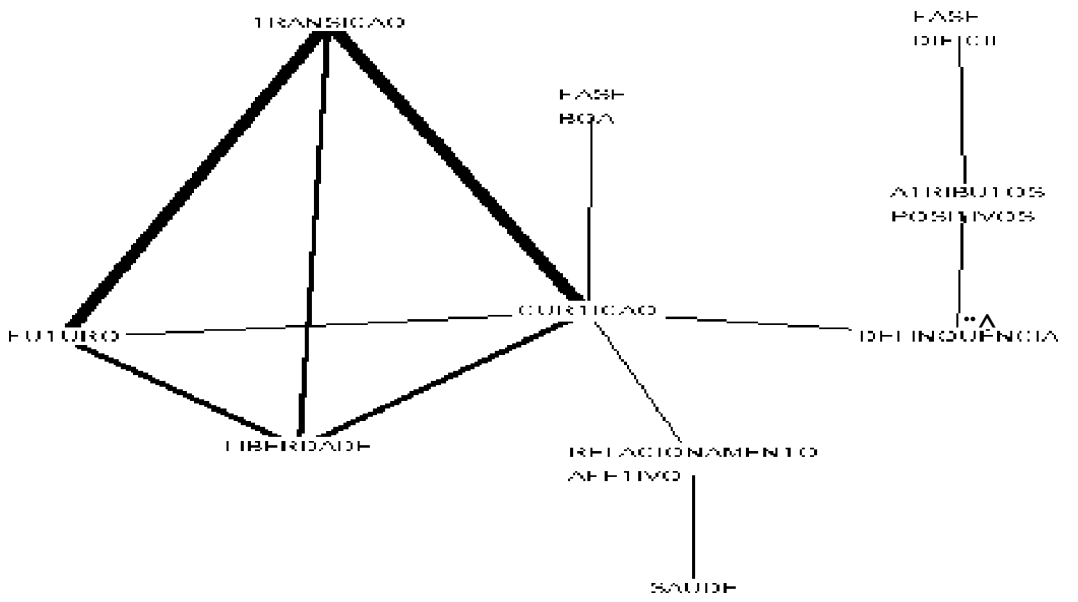

Figura 4. Gráfico de análise de similitude das categorias relacionadas à adolescência entre os sujeitos do interior $(n=180)$. 
O gráfico da árvore máxima (Figura 4) apresenta-nos uma configuração diferente das duas anteriores, como era esperado

$\mathrm{Na}$ Figura 4, observamos que a categoria Transição está conectada às categorias Futuro e Curtição por uma linha tripla e à categoria Liberdade por uma linha dupla e que a categoria Liberdade está relacionada às outras categorias por uma linha dupla. Das outras ligações que constam no gráfico, todas são feitas por linhas simples.

A partir dessa configuração, observamos que a categoria Transição é o elemento central e que isso permeia a idéia do que é a adolescência. Para esses participantes, eles se encontram no período de transição para uma vida adulta, uma vez que o futuro, para eles, está próximo, já que para a maioria, este encontra-se após o término do ensino médio, do qual saem como profissionais. Esse período de transição envolve maior liberdade e curtição. O elemento curtição também está relacionado a Relacionamento Afetivo, Fase Boa e Delinquiência, como nos gráficos anteriores. A diferença está que Delinqüiencia liga-se diretamente a Atributos Positivos que, por sua vez, está relacionado à Fase Dificiil. Isso nos demonstra que esses adolescentes percebem a adolescência como uma fase difícil e por isso é preciso ser uma boa pessoa, ser responsável e ter um bom caráter para evitar a delinqüência. Também indica-nos que a relação Atributos Positivos e Delinqüiencia, para esses participantes é mais forte e clara.

\section{Discussão}

Terceiro Nível: A Ancoragem da Adolescência

As duas abordagens utilizadas nos permitiram identificar com sucesso o que é ser adolescente para os participantes pesquisados. Foi verificado que, apesar de existirem pontos em comum, o viver adolescente se diferencia de acordo com a inserção sócio-cultural, confirmando que a condição da adolescência é historicamente construída e determinada, como aponta Margulis (2001)

De acordo com os dados, observamos que o nível de escolaridade dos pais dos participantes da zona urbana é mais elevado do que o dos pais do outro grupo. Também observamos que existe um maior número de mães dos participantes da zona rural, se comparados com as mães dos participantes do grupo da zona urbana, que não exercem atividades remuneradas e permanecem em casa com a responsabilidade dos servicos domésticos. Estes dados juntamente com os dados fornecidos peloIBGE (1999, 2000: www.ibge.gov.br) e Comissão Econômica para América Latina e Caribe (1993) (Durston, 2001) indicamnos duas formas de viver o mundo. Como expõe Sobrinho (1998), os indivíduos “estão inseridos em determinados espaços onde se impõe a apreensão diferenciada dos objetos sociais que constituem os diferentes sistemas de referências identitárias e dão visibilidade aos atores" (p. 120), ou seja, as representações sociais não se dão em um vazio social, e sim, em um espaço repleto de significações, opiniões, desejos e produções simbólicas; conseqüentemente, a estrutura e o conteúdo de cada representação se configura de acordo com um espaço social com a história de vida e o contexto em que o indivíduo se encontra. Tanto o nível de escolaridade como a inserção no mundo do trabalho podem ser fatores que contribuem para a produção de diferenças no contexto de cada um dos grupos.

As diferenças entre os espaços sociais são de fundamental importância para compreendermos as diferentes formas de viver a adolescência. Foram observados pontos comuns entre os grupos, como o vocabulário utilizado para identificar o que é adolescência na questão de palavra indutora. A partir disso, obtivemos na análise das evocações, as mesmas categorias; entretanto, ao executarmos a análise de similitude, observamos que a estruturação das RS é diferente para os grupos, já que as palavras associam-se de maneira diferente.

Um ponto comum entre os grupos que merece atenção aparece como resultado do levantamento dos elementos de representação pelo EVOC. A palavra que se apresentou em primeiro lugar de acordo com a freqüência e a ordem de evocação foi alegria. A partir disso, podemos dizer que esta palavra tem grande probabilidade de compor o núcleo central da RS de adolescência.

A palavra alegria representa o "estado de espírito" do ser adolescente e está relacionada a uma visão estereotipada do adolescente cheio de vida e energia e que está mais interessado em divertir-se do que em se manter informado dos acontecimentos à sua volta e no mundo, reproduzindo a visão tradicional da adolescência. Sobre essa forma de ser do adolescente, também verificamos, como nos lembra Cárdenas (2000), que a imagem e a expectativa sociais de uma conduta influem no desenvolvimento da mesma. Dessa forma, o próprio sujeito interioriza o estereótipo e muitas vezes se comporta de acordo com ele.

Apesar de a palavra alegria, na análise feita pelo EVOC, aparecer como elemento de grande significância para os dois grupos, ao observarmos o conjunto de dados verificamos que este conceito de alegria aparece com mais intensidade no grupo de adolescentes da zona urbana, representada pela classe Curtição

Os adolescentes da zona urbana freqüentam uma escola particular, provavelmente freqüentam cursos de línguas e participam de outras atividades extracurriculares. Sua preocupação está em sair com os amigos, passar de ano e escolher o curso que irá fazer na faculdade. O futuro para esses participantes ainda está distante. Eles precisam primeiro passar no vestibular, fazer o curso superior para, então, pensar em uma vida profissional. O período de transição da infância para a idade adulta é maior. Sendo assim, podemos observar que, quando estes falam do futuro, dizem apenas os problemas que precisam evitar para alcançá-lo, como exemplo, drogas, gravidez indesejada, doenças sexualmente transmissíveis, entre outras. O futuro para eles é idealizado, ou seja, não é concebido a partir de uma realidade, e sim, 
sobre o objetivo de ser feliz. A partir disso, verificamos que o discurso destes relaciona-se principalmente ao presente.

O discurso mais significativo dos adolescentes da zona urbana refere-se à curtição, à liberdade, ao relacionamento afetivo, aos problemas e também ao fato de a adolescência ser um período de transição. Esses elementos representam o presente imediato, podemos dizer que a pergunta que circula entre os adolescentes é: "Qual é a balada/rock de hoje?" Esses adolescentes valorizam poder sair com os amigos e de preferência, sem hora para voltar, ir a festas, "ficar" com meninas/meninos, mas sabem que se exagerarem e não tomarem o devido cuidado poderão se prejudicar. Também, em seu discurso, mencionam a importância do apoio dos pais, dos amigos e da escola para que ensinem e expliquem o que fazer, como agir em situações de perigo.

O discurso é dividido em dois pólos: curtição e apoio. Ao mesmo tempo em que eles precisam de liberdade para se divertir, precisam do apoio e da proteção para sentir-se seguros. A forma como vivem se assemelha à forma como uma criança é criada. O seu ambiente é controlado ora pela familia, ora pela escola, para que brinquem com tranqüilidade com seus pares. A diferença é a maneira de brincar. Com isso, vemos que o apoio e a proteção são elementos significativos para a vida e que a responsabilidade para seu futuro está, neste momento, colocada em agentes externos (pais, boa escola, entre outros).

Ao analisarmos com mais detalhe esse discurso, podemos observar que o verbo que melhor representa é o verbo TER. Para esses participantes terem uma vida e um crescimento saudável, precisam ter liberdade, ter bons pais, ter amigos, ter uma boa escola, ter segurança, ter dinheiro, em outras palavras, precisam ter apoio e um ambiente seguro. Essa forma de pensar ancora-se no sistema econômico em que vivemos que valoriza quem tem mais. A partir disso, também verificamos que esse discurso vai além das necessidades básicas, tornando-se importante ter boas roupas (andar na moda), ter carro, entre outros. Esse discurso pode tornar-se trágico para alguns adolescentes que fazem parte desse grupo, mas não podem acompanhar as suas exigências para serem aceitos e transitar neste sem problemas.

Ratificando a proposição de Margulis (2001) sobre a pluralidade da adolescência, para os adolescentes da zona rural, a adolescência é um tanto diferente da experienciada pelos adolescentes da zona urbana. Para aqueles, ao contrário, o futuro está muito próximo: o fim do ensino médio. O ensino médio técnico é dado em turno integral, durante um período os alunos têm aulas do ensino médio (história, português, matemática, entre outras) e no outro têm aulas práticas específicas do curso técnico. Essas aulas práticas exigem que os alunos trabalhem e se responsabilizem pelo trabalho executado. O ensino médio técnico significa uma grande conquista para esses participantes, pois não seguirão a profissão de agricultor, mais comum naquela região, estarão Psicologia: Reflexão e Crítica, 2003, 16(3), pp. 555-568 qualificados para trabalharem como Administradores de Fazenda. Terminado o ensino médio esses participantes estarão, em sua grande maioria, em busca de emprego. Isso significa que a maioria irá trabalhar, ganhar dinheiro para futuramente estabelecer uma família.

A partir deste contexto, entendemos melhor o que a adolescência significa para esses participantes. A adolescência além de ser uma fase de curtição, de liberdade, é a fase de definição da vida futura, da vida adulta. Por isso é muito importante que o adolescente siga o caminho certo, ou seja é importante que ele seja responsável e, portanto, seja um bom aluno, um bom filho, um bom amigo e siga em busca dos seus sonhos. As regras para seguir o caminho certo são claras e precisam ser seguidas, caso contrário o adolescente é considerado rebelde e com grande probabilidade de se tornar um delinqüente. $O$ verbo predominante neste discurso é o SER. O adolescente precisa ser muito bom para alcançar os seus objetivos, depende basicamente dele se quiser chegar a algum lugar. Por isso, vivenciam a adolescência como uma fase difícil e complicada. O grupo de participantes da zona urbana também menciona que esse é um período difícil, contudo esse discurso está mais relacionado à visão típica da adolescência como um período de tempestade e tormenta.

O TER e o SER são dois discursos que representam a forma de viver de cada grupo. O TER exprime o nosso sistema econômico e a cultura consumista em que ser é definitivamente algo que não faz nenhum sentido desatrelado da posse. A posse dá sentido ao ser, à medida que dependendo da quantidade e da qualidade dos produtos de posse a pessoa é qualificada.

O discurso SER, a princípio, pode parecer contraditório ao TER, pois pode-se pensar que, neste caso, o SER representa a humanidade, a experiência máxima do ser humano. Entretanto, não é o que ocorre. O discurso SER acontece em função do TER, pois revela que é preciso SER para TER. Sendo assim, é preciso ser um exemplo de pessoa para ter algo. Em outras palavras, é preciso ser um bom aluno, ser um bom filho, ser uma boa pessoa, para ter uma oportunidade de trabalho para deixar de ser um simples agricultor. A esperança de uma oportunidade de trabalho está atrelada à esperança de ter uma casa, de ter um carro entre outras coisas. O esforço é valorizado, pois acredita-se que é por meio do esforço pessoal que as oportunidades são alcançadas. Essa forma de pensar também ancora-se no sistema econômico em que vivemos, que deposita no sujeito a responsabilidade de alcance de sucesso, desconsiderando que as oportunidades não são iguais entre as classes.

Os dados desmistificam a romantização da vida no campo. E comum confrontar-se zona urbana e rural atribuindo à vida na zona urbana o fortalecimento do individualismo, do egoísmo, e pensando a vida na zona rural como fortalecida por relações de cooperação, forjando pessoas melhores, mais solidárias e atentas às necessidades do outro. À primeira 
vista, os dados sobre o discurso TER e SER pareceriam corroborar estas diferenças, no entanto, uma apreensão mais acurada mostrou que o SER, para os adolescentes da zona rural, é apenas um caminho para o TER. As aspirações destes sobre o TER podem ser mais modestas, mas estão presentes todo o tempo. Isso pode indicar que, para eles, já está mais claro que suas características pessoais serão importantes na construção de um futuro melhor e que, para os adolescentes da zona urbana, esta questão ainda não se coloque, marcando uma diferença expressiva na forma como os dois grupos vivem a adolescência: enquanto uns reconhecem a própria responsabilidade na construção do futuro, outros o atribuem às condições que lhes forem oferecidas.

Ao longo deste trabalho discutimos a adolescência utilizando o referencial teórico das Representações Sociais. O método de análise dos resultados utilizado apontou a variável localidade, delimitada pela proximidade com o urbano ou com o rural, como de maior significância para o entendimento dos diferentes discursos entre o grupo de adolescentes. No entanto, para que o conhecimento sobre a representação social da adolescência entre os adolescentes seja ampliado outros estudos deverão ser realizados para a verificação da forma como outras variáveis participam desse processo.

Pudemos verificar que a forma como o adolescente vive a sua adolescência está ancorada na apreensão das concepções mais tradicionais de adolescência, o que não impede que assuma diferentes configurações, corroborando assim a tendência mais recente que propõe a adolescência como uma condição historicamente construída e, por isso, múltipla.

\section{Referências}

Abric, J. C. (1998). A abordagem estrutural das representações sociais. Em A. S. P Moreira \& D. C. Oliveira (Orgs.), Estudos interdiciplinares de representacia social (pp. 27-38). Goiânia: AB

Abric, J. C. (2001). Méthodologie de recueil des représentaions sociales. Em J. C Abric (Org), Pratiques sociales et representations ( $3^{\mathrm{a}} \mathrm{ed}$.) (pp. 217-238). Paris : Press Universitaires de France.
Ariès, P. (1978). História social da criança e da familia. Rio de Janeiro: Guanabara. Banchs, M. A. (2000). Aproximaciones procesuales y estructurales al estúdio de representaciones sociales. Paper on Social Representations, 9, 3.1- 3.15

Cárdenas, C. J. (2000). Adolessendo: Um estudo sobre a constituição da identidade do adolescente no âmbito da escola. Tese de Doutorado não-publicada, Curso de Pós- Graduaç̃ão em Psicologia, Universidade de Brasília. Brasília, DF.

Doise, W. (2000, abril). Da psicologia social à psicologia societal. Conferencia proferida por ocasião da aula inaugural do Instituto de Psicologia, UnB, Brasília.

Durston, J. (2001). Juventud rural y desarollo en américa latina: Estereotipos y realidades. Em S. D. Burak (Org.), Adolescência juventud en américa latina (pp. 99-116). Cartago: Libro Universitário Regional.

Erikson, E. (1968). Identity: Youth and crisis. New York: Norton.

Erikson, E. (1968). Identity: Youth and crisis. New York: Norton.
Instituto Brasileiro de Geografia e Estatística, Departamento de População e

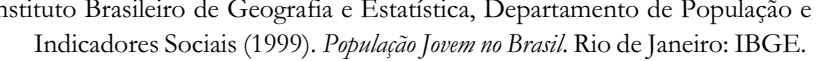
Indicadores Sociais (1999). Populaạão Jovem no Brasil. Rio de Janeiro: IBGE.
Margulis, M. (2001). Juventud: Una aproximación conceptul. Em S. D. Burak Margulis, M. (2001). Juventud: Una aproximación conceptul. Em S. D. Burak
(Org.), Adolescéncia y juventud en américa latina (pp. 41-56). Cartago: Libro Universitário Regional

Mead, M. (1967). Adolessenciay cultura en Samoa. Buenos Aires: Paidós.

Moscovici, S. (1978). A representação social da psicanálise. Rio de Janeiro: Zahar. (Original publicado em 1961)

Muuss, R. E. (1976). Teorias da adolescência. Belo Horizonte: Interlivros.

Oliveira, M. A. C. \& Egry, E. Y. (1997). A adolescência como um constructo social. Revista Brasileira do Crescimento e Desenvolvimento Humano, 7(2), 12-21. OPS (1998). La salud en las Américas (Vol. 1). Washington, DC

Dissertac̃a de (1), A. S. M. (200). Mahbo, adulto, branco, sempre no comando? Dissertação de Mestrado não-publicada, Curso de Pós Graduação em Psicologia,
Universidade de Braślia. Brasilia, DF.

Sá, C. P. (1996). Núcleo central das representacōes sociais. Petrópolis, Rio de Janeiro:

Vozes.
Sá, C. P. (1993). Representações sociais: o conceito e o estado atual da teoria. Em M. J. Spink (Org.), O conbecimento no cotidiano: as representacōoes sociais na perspectiva da psicologia social (pp. 19-45). São Paulo: Brasiliense.

Sobrinho, M. D. (1998). "Habitus" e representações sociais: Questões para o estudo de identidades coletivas. Em A. S. P. Moreira \& D. C. Oliveira (Orgs.), Estudos interdisciplinares de representacáces sociais (pp. 117-130). Goiânia: AB.

Trindade Z A. (1996). Representação social. "Modo de conhecer" no cenário da saúde. Em Z A. Trindade \& C. Camino (Oross), Coletanneas do ANPEPP. Cognicãa e juíro moral. (Vol. 1, 6, pp. 45-59). Rio de Janeiro: Associação Cognição e juizo moral. (Vol. 1, 6, pp. 45-59). Rio de Janeiro: Ass
Nacional de Pesquisa e Pós-Graduação em Psicologia - ANPEPP.

Wagner, W. \& Kronberger, N. (2002). Palavras-chave em contexto: Análise estatística de textos. Em M. W. Bauer \& G. Gaskell (Orgs.), Pesquisa qualitativa com texto, imagem e som: um manual prático (pp. 416-441). Petrópolis: Vozes.

Recebido: 29/11/2002 $1^{a}$ Revisão: 18/02/2003 Última Revisão: 05/05/2003 Aceite final: 09/05/2003

Sobre as autoras

Priscilla de Oliveira Martins é Mestre em Psicologia pela Universidade Federal do Espírito Santo.

Zeidi Araújo Trindade é Professora Doutora da Universidade Federal do Espírito Santo.

Ângela Maria de Oliveira Almeida é Professora Doutora da Universidade de Brasília. 